\title{
Rethinking Open Innovation Beyond the Innovation Funnel
}

\section{Wim Vanhaverbeke}

\author{
"We are bound no longer by the straightjacket of the past." \\ Douglas MacArthur (1880-1964) \\ General of the Army (United States)
}

\begin{abstract}
In his article, I first argue that open innovation can be applied in situations where companies do not themselves develop new products or services. As a consequence, open innovation becomes relevant for a much larger group of organizations than previously considered. Second, I argue that open-innovation scholars have insufficiently differentiated open-innovation initiatives in terms of their impact on companies' growth: some open-innovation initiatives lead to incremental innovations in an existing business while, in other cases, open-innovation initiatives are used to establish completely new businesses. Both arguments illustrate the need to integrate open-innovation initiatives into the strategy of the firm.
\end{abstract}

\section{Introduction}

Do we need to rethink open innovation? Is this really necessary? In this article, I provide a few reasons why open innovation has to be disconnected from the innovation funnel. Once open innovation is freed from this straightjacket, we might give it a "second wind" for additional growth.

Open innovation has always (implicitly) focused on new product introductions. This is illustrated by the central place of the (open) innovation funnel in Chesbrough's seminal book on open innovation (2003; tinyurl .com/d2l6bqx). Open innovation has been defined in terms of inside-out or outside-in innovation. These two terms implicitly refer to the "open" innovation funnel where external knowledge is acquired to strengthen internal competencies and accelerate the innovation process in the company, and from where unused, internal knowledge is monetized through external paths to market. External knowledge is insourced to develop a new product or business, or internal knowledge is sold to another organization, which deploys it for its own product development. In this article, I provide two arguments to disconnect open innovation from the innovation funnel, opening in this way new directions for future research in this field. First, I argue that organizations in different types of industries can benefit from open innovation even when they are not themselves developing new products or services. This change in perspective makes open innovation relevant for a much broader range of organizations than before. Second, open innovation, with its main focus on the innovation funnel, has implicitly been focusing on R\&D projects that, if successful, would bring new growth to existing businesses. Innovation scholars made few attempts to compare the case where open innovation is a means to accelerate growth of existing businesses with the case where it is used to establish completely new businesses.

Both arguments illustrate the need to integrate openinnovation initiatives into the strategy of the firm. It is time that scholars analyze how managers follow a stepwise process to link firms' strategy to open-innovation practices and take the integration of open innovation into strategy seriously.

I explore these two themes in more detail in the following two sections. In the conclusions, I focus on the consequences of this attempt to broaden open innovation for both practitioners and academia. 


\title{
Rethinking Open Innovation Beyond the Innovation Funnel
}

\author{
Wim Vanhaverbeke
}

\section{Open Innovation Beyond New Product Development}

Chesbrough and Vanhaverbeke (2013; in press: Exploring the Next Wave of Open Innovation Research, Oxford University Press) show that open innovation can be applied to many more situations than the usual cases where product innovation is essential. We claim that product development is only one activity of the many business activities where open innovation is applicable. Product innovation is not an option in many industries: in many service-oriented industries, product innovation is not generating value for the customer, because they focus on creating solutions for customers rather than producing and selling products. Moreover, in many manufacturing industries, companies produce and sell commodities, and, consequently, product innovation is per definition not possible. Chesbrough and Vanhaverbeke (2013; in press) propose that, in these industries, a company (the focal firm) should first determine its strategic drivers that can be leveraged to gain competitive advantage. Next, technological innovations in other companies may be useful in leveraging the identified strategic drivers. Therefore, the focal firm has to set up a network (or a so-called innovation ecosystem) with these companies: technological innovations in the latter will generate a competitive advantage in the former. In short, we should not automatically link open innovation to new product or business development, but rather look for specific competitive drivers relevant in particular situations but not in others.

As an example, take the crude-oil business at a large oil company. The product that this business unit is selling is inevitably a commodity, and product innovation is by definition excluded (at least at the business-unit level). However, as in each business, competitive advantage in the crude-oil business is determined by a number of strategic drivers. Two important strategic drivers are the early detection of large oil wells and the effective drilling of these wells. Competitiveness in the crude-oil business depends on various technologies that increase the productivity of exploration and extraction. Oil companies have to detect the richest oil wells earlier than competitors and drill them more effectively through new technologies that allow them to extract oil at greater depths. Although the oil industry is dominated by large companies with strong R\&D capabilities, they rely on specialized oil-services companies such as Schlumberger and others to develop new technologies for oil exploration and extraction: the oil-services sector is a beacon of innovation within the energy industry. Oilservices firms typically receive more patents each year than most of the large integrated oil companies. The oil company gains a competitive advantage if it partners with Schlumberger (usually in combination with other specialized services companies), who has leading-edge exploration and drilling technology. An oil company can set up a research program with these partners and (co-)finance the research and development of new exploration and drilling technology. They become strategic partners in advancing this technology. The oil company will typically require exclusive use of the technology for several years before Schlumberger can sell the technology to other oil companies.

The example of the crude-oil business in oil companies is just one example of how companies that could not be considered as "open innovators" still can drive competitive dynamics through innovation ecosystems. In this setting, it is essential that the partnering companies have networked business models, meaning that the companies' business models that are mutually interdependent. As an example of a networked business model, take the iPhone: Apple creates value by setting up a platform for apps, and the number of apps determines the value of an iPhone for the customer. Obviously, the appmaker depends on the platform to create his value for the customer. Networked or linked business models are in turn a recent development that have received the attention of Osterwalder and Pigneur, authors of the bestselling book Business Model Generation (2009; tinyurl.com/cadq9x9). Chesbrough and Vanhaverbeke (2013; in press) provide other examples, such as SkyNRG (skynrg.com) and Better Place (betterplace.com), where a combination of linked business models and open innovation can be used to leverage any strategic driver.

Within this extended open-innovation framework, new product development should be considered as a specific competitive driver relevant in particular situations but not in others. To extend the applicability of open innovation, we have to start from the strategy of a business, identify the key competitive/value drivers that should be enacted upon, spot and select the potential innovation partners, and set up a joint project to develop technologies or solutions that will strengthen the firm's competitive drivers. Thus, even in absence of any product or service innovation in the business, firms can still "nurture" their network of innovation partners and value-chain partners to become more competitive. This extension of the original open-innovation concept may lead to entirely new developments in this research field: 


\title{
Rethinking Open Innovation Beyond the Innovation Funnel
}

\author{
Wim Vanhaverbeke
}

1. Strategy as starting point: This shift away from product innovation shows that the competitive position of firms may rely on a broad set of value drivers, going from process innovations, an increase in the productivity of a business, or a improvement of the quality or usability of products. Increasing throughput time, reducing operational complexity and costs, or integrating processes are other examples. Which one to focus on depends on the business context, but in each case, the focal firm can set up a joint research initiative and encourage (technology) partners to accelerate innovation in a particular field. Therefore, instead of starting from the need to open up during a new product innovation process, managers should first identify strategic drivers that can be leveraged by new (technological) developments in partnering organizations.

2. Wider applicability of open innovation: extending open innovation in this way makes it more relevant for companies who are recipients of technologies/innovations, such as service industries, low-tech manufacturing industries, and governments. Recipient organizations can initiate and orchestrate the collaborative initiative while technology providers are implementers within this framework. As a result, open innovation is not only relevant for innovating new product innovations but also for innovating and improving services; processes; technologies; management practices; ideas/concepts, strategies, and business models; competence building; etc., regardless of the industry.

3. Need to change the theoretical open-innovation framework: The extension of the open-innovation framework also implies that the open-innovation funnel can no longer remain the central framework for open innovation. It should be replaced by a new framework that entails a number of items that are central in the innovation-ecosystem literature (Adner, 2012; tinyurl .com/dxxkw4a).

4. Managing innovation ecosystems as the new imperative: Nambisan and Sawhney (2010; tinyurl.com/cr4zcy5) have shown how such an innovation ecosystem has to be managed. However, they limit their attention to firms who themselves are technological innovators and require an ecosystem to get the technology developed and adopted. Our approach is different, leading to a different type of ecosystem and different guidelines for managing the ecosystem appropriately.

\section{Enriching and Broadening Open Innovation by Connecting it to Strategy}

Strategic concepts already took an implicitly central place in seminal open-innovation publications (Chesbrough, 2003: tinyurl.com/d2l6bqx; 2006: tinyurl.com/c4cwoha). The business model, for instance, is a central concept in the open-innovation funnel because it determines what external knowledge a firm needs to source from external partners and what internal knowledge can be licensed or sold to other companies. In this way, business models and strategy are already at the heart of open innovation.

Open innovation has to be embedded in firms' strategy to understand the real value of open-innovation initiatives in large companies. I want to illustrate this assertion with three well-known cases: P\&G's Printed Pringles, the Swiffer Duster of the same company, and DSM's Emerging Business Areas (EBAs). These examples of open innovation are usually classified as "successes in open innovation" both in professional journals as well as in academic journals. However, these three examples have a different impact on the growth of the company. The Pringles example represents a minor change in the business, the Swiffer duster is an entire new product for $P \& G$, and the EBAs are a bold bet of DSM to generate complete new divisions at DSM within three to 10 years. Open-innovation projects should not be differentiated according to their impact on current or future growth of the company. These projects play a different role in the strategy of companies. We only can estimate the strategic value of different open-innovation approaches if we integrate open innovation into the business and corporate strategy of companies. Several practice-oriented authors have detailed how managers can follow a stepwise process to successfully link firms' strategy to open-innovation practices (Slowinsky and Sahal, 2010: tinyurl.com/d3n8q8u; Kirschbaum, 2005: tinyurl.com/cqzr5xn). Yet, the link between open innovation on the one hand and strategy on the other hand has received scant attention in the academic literature. In contrast with the rapid growth of the open-innovation literature, only few articles have been focusing on open innovation and strategy (Chesbrough and Appleyard, 2007: tinyurl.com/bp9gmee; Dittrich and Duysters, 2007: tinyurl.com/c6rvc6h).

One way to broaden the focus of the current open innovation literature is to link it explicitly to corporate strategy. Popular open-innovation cases illustrate how a firm can benefit using external knowledge sources to de- 


\title{
Rethinking Open Innovation Beyond the Innovation Funnel
}

\author{
Wim Vanhaverbeke
}

velop new products in existing businesses. This overemphasis on the use of open innovation in existing businesses eclipses other potential strategic uses. At DSM, management has established the EBAs, where complete new businesses or divisions are developed and incubated at the corporate Innovation Center to drive future (and not current) growth of the company by establishing new businesses that do not yet exist in the company (see Vanhaverbeke and Peters, 2005: tinyurl.com/ckk6llb; Wijen et al., 2011: tinyurl.com/c8uob7j). These businesses are developed in collaboration with a broad range of external (technology) partners. The collaboration with external partners can hardly be compared with the inter-organizational collaboration when companies engage in new product development for existing businesses (as in the two P\&G cases mentioned above). In sum, open-innovation projects play different roles in the strategy of companies and we need to have a better understanding of how different forms of organization and management help companies to team up with different types of external partners to realize incremental growth in current businesses or growth in completely new businesses. Different strategic growth targets will lead to different ways to organize open innovation, different departments in the organization will be responsible to lead the projects, and the type of partners will also be different depending on the strategic role of the projects. Developing new products in existing businesses is only one possible strategic objective of open-innovation projects. Sourcing knowledge from partners can also be done for other strategic purposes. The development and incubation of early-stage ventures in business areas that are targeted by top management as growth areas (beyond the existing divisions in the company) is another one. Similarly, a firm may use open innovation to realize major corporate changes in the company. Organizing open innovation for reasons of corporate growth and renewal also implies that a firm has to develop new competencies that are not present internally. This offers an interesting perspective on how companies develop new long-term competencies. This, in turn, can be linked to interesting developments about dynamic capabilities.

What are the implications of this change in perspective for future research on open innovation?

1. Strategy as starting point. Introducing open innovation is pointless when it is not guided by and embedded in firms' strategy. There is an urgent need to integrate open innovation into strategy and differentiate open-innovation projects according to their role in the strategy.
2. Understand the diversity of open-innovation projects: The integrating of open-innovation activities into corporate strategy allows us to explain the large interorganizational differences in implementing open innovation successfully. A careful analysis of the role of open innovation in firms' strategies provides a better understanding of the multitude of organizational and managerial practices which are nowadays all labeled as open innovation. The diversity of the open-innovation activities is in most cases the result of different strategic objectives firms want to reach with openinnovation activities.

3. Link open innovation to corporate growth and corporate renewal literature: The scope of open-innovation activities is, in the current literature, usually determined by the business model of mainstream businesses in a company. The potential benefits of open innovation from a corporate-growth and corporate-renewal perspective are virtually nonexistent in the literature: several companies have successfully used open innovation in growing entirely new businesses outside the existing business, with a fundamentally different approach to open innovation.

4. Exploration/exploitation: Once open innovation is tightly linked to corporate (growth) strategy, scholars can use a broad stream of literature about exploration/exploitation (March, 1991; tinyurl.com/8xqlyp5) and the need to have an ambidextrous company (Tushman and O'Reilly, 1996: tinyurl.com/7y8lhm6; Janssen et al., 2012: tinyurl.com/bv9pe5g). "An ambidextrous organization is one that is capable of simultaneously exploiting existing competencies (e.g., satisfying existing customers) and exploring new opportunities (e.g., developing new products)" (Schreuders and Legesse, 2012; timreview.ca/article/522).

5. Capability building and dynamic capabilities: When open innovation is embedded as an essential element in corporate growth strategy, we can expect that new competence building will become a central topic. Open innovation is in this case not only instrumental in developing a product during its journey from research to market launch. In corporate initiatives that envision to grow into new technologies and business areas, new competencies have to be built along the way. This offers an opportunity to put the role of open innovation in developing new competencies and dynamic capabilities into the spotlight (Teece et al., 1997: tinyurl.com/cu49okc; Teece, 2007: tinyurl.com/c3m59tv; Helfat et al., 2007: tinyurl.com/cgodvfw). 


\section{Rethinking Open Innovation Beyond the Innovation Funnel}

Wim Vanhaverbeke

\section{Conclusions}

When open innovation was launched as a new concept in 2003, it was tightly linked to other concepts such as new product development, the innovation funnel, and business-model change in large companies. Gradually the scope of open innovation has been broadened, introducing new concept such as open business models and open services innovation. In my view, it is time for a new major step forward by integrating open innovation into strategy. This has been a major gap in the open-innovation literature for the last 10 years and this gap has been hampering the progress of open innovation as a useful concept in the mainstream innovation literature.

I have been focusing on two topics in this article. First, open innovation can be useful for companies that are not involved in new product development activities. I have described some examples where companies that are not involved in new product development can benefit by setting up a collaborative strategy wherein the open-innovation activities of other companies (in different industries) help improve the competitive strength of the former. Second, the full potential of open innovation cannot be realized as long as it is not connected to corporate strategy. Some companies use open innovation in a quite different way than the standard case studies we can read in the literature. These firms integrate open innovation tightly with corporate growth and corporate renewal objectives. This leads to a new application of open innovation: when the collaboration with technology partners takes place mainly to build new internal (technological) competences.

Both topics illustrate how important it is to integrate open-innovation initiatives into the strategy of the firm. Several practice-oriented authors described already how managers follow a stepwise process to link firms' strategy to open-innovation practices. It is time that the academic literature takes the integration of open innovation into strategy seriously.

\section{About the Author}

Wim Vanhaverbeke is a Professor at the University of Hasselt in Belgium. He is also Visiting Professor at ESADE Business School in Spain and at the National University of Singapore. He has published in several international journals and is co-editor, with Henry Chesbrough and Joel West, of Open Innovation: Researching a New Paradigm, a book about the research challenges related to open innovation. He is a dedicated open-innovation researcher collaborating with different partners in universities and companies around the globe. He established the European Innovation Forum with Henry Chesbrough in 2012. He is frequently invited to speak at leading international conferences, and he is an adviser for several globally operating companies. He is co-editing a new book about open innovation, which will be published in 2013 .

Citation: Vanhaverbeke, W. 2013. Rethinking Open Innovation Beyond the Innovation Funnel. Technology (cc) BY Innovation Management Review. April 2013: 6-10.

Keywords: open innovation, new product development, strategy, innovation funnel 